\title{
Comparison of Strength-Maturity Models Accounting for Hydration Heat in Massive Walls
}

\author{
Keun-Hyeok Yang ${ }^{1), *}$, Jae-Sung Mun ${ }^{2)}$, Do-Gyeum Kim ${ }^{3)}$, and Myung-Sug Cho ${ }^{4)}$
}

(Received May 6, 2015, Accepted January 31, 2016, Published online February 19, 2016)

\begin{abstract}
The objective of this study was to evaluate the capability of different strength-maturity models to account for the effect of the hydration heat on the in-place strength development of high-strength concrete specifically developed for nuclear facility structures under various ambient curing temperatures. To simulate the primary containment-vessel of a nuclear reactor, three 1200 -mm-thick wall specimens were prepared and stored under isothermal conditions of approximately $5{ }^{\circ} \mathrm{C}$ (cold temperature), $20{ }^{\circ} \mathrm{C}$ (reference temperature), and $35^{\circ} \mathrm{C}$ (hot temperature). The in situ compressive strengths of the mock-up walls were measured using cores drilled from the walls and compared with strengths estimated from various strength-maturity models considering the internal temperature rise owing to the hydration heat. The test results showed the initial apparent activation energies at the hardening phase were approximately 2 times higher than the apparent activation energies until the final setting. The differences between core strengths and field-cured cylinder strengths became more notable at early ages and with the decrease in the ambient curing temperature. The strength-maturity model proposed by Yang provides better reliability in estimating in situ strength of concrete than that of Kim et al. and Pinto and Schindler.
\end{abstract}

Keywords: high-strength concrete, in situ strength, mock-up, hydration heat, maturity, curing temperature.

\section{List of Symbols}

$D \quad$ Diameter of core

$E_{a}(i) \quad$ Apparent activation energy at time step $i$

$E_{i} \quad$ Initial apparent activation energy during the hardening phase

$E_{s} \quad$ Apparent activation energy until the final setting time

$F_{d} \quad$ Correction factor to damage to the surface of the core samples

$F_{\text {dia }} \quad$ Correction factor to account for the diameter of the core samples

$F_{H / D} \quad$ Correction factor to account for the slenderness of core samples

$F_{m c} \quad$ Correction factor to account for the core moisture content

${ }^{1)}$ Department of Plant Architectural Engineering, Kyonggi University, Suwon 443-760, Korea.

*Corresponding Author; E-mail: yangkh@kgu.ac.kr

${ }^{2)}$ Department of Architectural Engineering, Graduate

School, Kyonggi University, Suwon 443-760, Korea.

${ }^{3)}$ Structural Engineering \& Bridges Research Division,

Korea Institute of Construction Technology,

Goyang 411-712, Korea.

${ }^{4)}$ KHNP-Central Research Institute, Korea Hydro \&

Nuclear Power Co., LTD, Daejeon 305-343, Korea.

Copyright $($ The Author(s) 2016. This article is published

with open access at Springerlink.com $f_{\text {core }} \quad$ Compressive strength of core samples

$H \quad$ Height of core samples

$k_{r} \quad$ Rate constant at the reference temperature

$k_{t} \quad$ Rate constant

$R \quad$ Universal gas constant $(=8.314 \mathrm{~J} / \mathrm{mol} / \mathrm{K})$

$R_{s p} \quad$ High-range water-reducing agent-cementitious material ratio by mass

$S$ Compressive strenth of concrete at an age of $t$

$S_{u} \quad$ Limiting strength of concrete

$S_{28} \quad$ 28-day compressive strenth of concrete

$\left(S_{28}\right)_{\operatorname{Tr}}$ 28-day compressive strenth of concrete under reference curing temperature

$T_{A 3} \quad$ Curing temperature at an age of 3 days

$T_{c}(i) \quad$ Curing temperature of concrete at time step $i$

$T_{r} \quad$ Reference curing temperature

$t \quad$ Concrete age

$t_{e} \quad$ Equivalent age

$t_{s} \quad$ Final setting time at a given temperature

$t_{s r} \quad$ Final setting time at the reference temperature

$t_{0} \quad$ Offset time at a given temperature

$t_{0 r} \quad$ Offset time at the reference temperature

$w / \mathrm{cm}$ Water-cementitious material ratio by mass

$\gamma \quad$ Ratio between estimated compressive strength of concrete and test results

$\gamma_{m} \quad$ Mean of the ratios between estimates and test results

$\gamma_{s} \quad$ Standard deviation of the ratios between estimates and test results

$\gamma_{v} \quad$ Coefficient of variation of the ratios between estimates and test results 


\section{Introduction}

Construction schedules for concrete structures significantly depend on the minimum stripping time for the concrete form work and shoring and the minimum concrete strength for applying a prestressing force to a structural element (Sofi et al. 2012; Vázquez-Herrero et al. 2012). Thus obtaining a higher strength gain of concrete at an early age is one of the most critical concerns for shortening the construction time for concrete structures. For this reason, the use of high-strength concrete (HSC) has been gradually encouraged for the fast-track construction of nuclear facility structures, especially in South Korea. The strength development of HSC is more sensitive to the curing temperature than normal-strength concrete (NSC) because the hydration rate of cement is greater at a lower water-cementitious materials ratio and a higher curing temperature (Kim et al. 2002a; Pinto and Schindler 2010). As a result, the strengthmaturity models established from the NSC test data using standard cylinders are frequently pointed out to overestimate the in situ strength of HSC, particularly under a cold temperature at an early age (Parsons and Naik 1985; Hulshizer 2001). However, the strength-maturity relationship for HSC is still an equivocal issue because of the limited available data, although the maturity method is used as an effective means of estimating strength development of in situ concrete (Sofi et al. 2012).

The strength-maturity relationship of concrete is traditionally determined using standard cubic or cylindrical specimens cured in a laboratory at standard temperature. However, as commonly recognized (Haug and Jakobsen 1990; Puciontti 2013; Uva et al. 2013), the curing histories of a standard-cured specimen and an in-place concrete member would not be identical. Thus, the strength development of a laboratory specimen would differ from that of a structure under construction. This difference may be primarily attributed to the heat of hydration, which produces a higher internal temperature in structural members than the surrounding environment (Kim et al. 2002b). Hence, a large difference between a cylinder's strength and the in situ strength is expected with an increase in the design strength of the concrete and/or member thickness. However, available data (Harris et al. 2000; Schrader 2007) dealing with the difference between standard-cured or field-cured cylinder strength and in-place strength for a mass concrete element are still scare, although the concept of equivalent age derived from the Arrhenius function has been primarily used as a maturity function to describe the temperature sensitivity of the reaction of cementitious materials. Furthermore, to reasonably estimate construction schedules for mass concrete structures under various temperatures, the reliability of the strength-maturity relationships needs to be ascertained for HSC used in massive concrete members.

The purpose of this study was to examine the differences in the compressive strength development between fieldcured cylindrical specimens and a mass concrete element made using HSC with a design strength of $55 \mathrm{MPa}$. The mixture proportions of the HSC were specifically determined based on its use in nuclear facility structures under different ambient temperatures in South Korea, while considering the hydration heat generation, economic efficiency and durability of the concrete (Yang 2014). To simulate the primary containment-vessel of a nuclear reactor, three 1200-mmthick mock-up wall specimens were prepared and cured under isothermal ambient temperatures of approximately 5, 20 , and $35^{\circ} \mathrm{C}$. The in situ compressive strengths of the mock-up walls were measured using cores drilled from the wall structures, in accordance with ASTM C42/C42 M (2011). The setting times, rate constants, and apparent activation energies of the prepared mixtures were also measured in accordance with ASTM procedures (2011) in order to calculate the equivalent age based on the Arrhenius function. The measured core strength was compared with the companion cylinder strength and estimates obtained from different maturity approaches (Kim et al. 2002a; Pinto and Schindler 2010; Yang 2014).

\section{Experimental Details}

\subsection{Concrete Mixtures}

To improve the economic efficiency by shortening the construction time and extending the expected service life of nuclear facility structures, a target of $55 \mathrm{MPa}$ was set for the 28-day compressive strength of concrete. Considering the workability and need to minimize the bleeding of concrete in the primary containment-vessel of a nuclear reactor with large diameter reinforcing bars, a value of $150 \pm 15 \mathrm{~mm}$ was selected for the target initial slump of the fresh concrete. For the targeted concrete strength and initial slump, tests of numerous laboratory mixtures were previously conducted under different ambient curing temperatures of approximately 5,20 , and $35^{\circ} \mathrm{C}$. As a result, three mixture proportions were specifically determined for use at the three ambient temperatures, as listed in Table 1 (Yang 2014).

According to the ambient curing temperatures, different supplementary cementitious materials (SCMs) were added as partial replacements for the cement. The heat of hydration and the rate of heat evolution in concrete commonly increase with increasing $\mathrm{C}_{3} \mathrm{~S}$ and $\mathrm{C}_{3} \mathrm{~A}$ contents of cement. On the other hand, the pozzolanic reaction is slower than $\mathrm{C}_{3} \mathrm{~S}$ hydration and it produces less heat than does cement hydration (Nili and Salehi 2010). As a result, concrete containing SCMs normally experiences slow hydration, accompanied by a lower temperature rise. Bamforth (1980) reported that ground granulated blast-furnace slag (GGBFS) as a partial replacement for ordinary portland cement (OPC) generates a lower temperature rise and a slower rate of increase than OPC mass concrete. The weight ratios of the SCMs selected for the three mixtures were as follows: $5 \%$ silica fume (SF) for the ambient curing temperature of $5{ }^{\circ} \mathrm{C}$, $50 \%$ GGBFS for a temperature of $20^{\circ} \mathrm{C}$, and a combination of $65 \%$ GGBFS and $5 \%$ SF for a temperature of $35{ }^{\circ} \mathrm{C}$. The three mixtures were identified as S5, G50, and G65S5 
Table 1 Concrete mixture proportions.

\begin{tabular}{|c|c|c|c|c|c|c|c|c|c|}
\hline \multirow[t]{2}{*}{ Mixtures } & \multirow{2}{*}{$\begin{array}{c}\text { Ambient } \\
\text { curing } \\
\text { temperature } \\
\left({ }^{\circ} \mathrm{C}\right)\end{array}$} & \multirow[t]{2}{*}{$w / \mathrm{cm}(\%)$} & \multicolumn{7}{|c|}{ Quantity $\left(\mathrm{kg} / \mathrm{m}^{3}\right)$} \\
\hline & & & Water & $\begin{array}{c}\text { Modified } \\
\text { cement }\end{array}$ & $\mathrm{SF}$ & GGBFS & Sand & Gravel & $R_{s p} *(\%)$ \\
\hline S5 & 5 & 34 & 155 & 433 & 23 & - & 737 & 941 & 1.5 \\
\hline G50 & 20 & 34 & 155 & 228 & - & 228 & 705 & 900 & 0.7 \\
\hline G65S5 & 35 & 34 & 155 & 137 & 23 & 296 & 703 & 897 & 0.5 \\
\hline
\end{tabular}

$* R_{s p}=$ high-range water-reducing agent-to-cementitious material ratio by mass.

based on the SCM replacements. For all three mixtures, the water-cementitious material ratio $(w / \mathrm{cm})$ and unit water content were fixed at 0.34 and $155 \mathrm{~kg} / \mathrm{m}^{3}$, respectively. To achieve the targeted initial slump, a high-range water-reducing admixture was also added, as given in Table 1. The main composition of this admixture was acrylic acid-acrylic ester copolymer, lignosulfonate, and sodium gluconate.

\subsection{Materials}

The chemical compositions of the cementitious materials are given in Table 2, which were obtained using an X-ray fluorescence (XRF) analysis. The cement that is commonly used for nuclear plant structures in South Korea was selected as the main binder. The chemical composition of the cement was modified to reduce the hydration heat generation. As a result, the chemical composition of the cement was close to that of a moderate heat cement. As compared with the common chemical composition of Type I portland cement specified in ASTM C150 (2011), the aluminum oxide $\left(\mathrm{Al}_{2} \mathrm{O}_{3}\right)$ content in the modified portland cement was lower by approximately $2 \%$, whereas the silicon oxide $\left(\mathrm{SiO}_{2}\right)$ content was $1 \%$ higher. From a potential Bogue composition (1955) of the mineral compounds based on the percentage of the given oxide in the total mass of the modified portland cement, the $\mathrm{C}_{3} \mathrm{~S}, \mathrm{C}_{2} \mathrm{~S}, \mathrm{C}_{3} \mathrm{~A}$ and $\mathrm{C}_{4} \mathrm{AF}$ contents were calculated to be $43.9,33.9,3.7$ and $11.6 \%$, respectively. This indicates that the $\mathrm{C}_{3} \mathrm{~S}$ and $\mathrm{C}_{3} \mathrm{~A}$ contents of the modified cement were 16 and $54 \%$ lower than those conventionally determined from the Type I cement, respectively, whereas $\mathrm{C}_{2} \mathrm{~S}$ content of the former was $37.6 \%$ higher than that of latter. The GGBFS, which conformed to ASTM C989 (2011), had a high calcium oxide $(\mathrm{CaO})$ content and a $\mathrm{SiO}_{2}-$ to- $\mathrm{Al}_{2} \mathrm{O}_{3}$ mass ratio of 2.29 . The basicity of the GGBFS calculated from the chemical composition was 1.94. The primary component of the $\mathrm{SF}$ was $\mathrm{SiO}_{2}$. The specific gravity and specific surface area of the cementitious materials were
3.15 and $3466 \mathrm{~cm}^{2} / \mathrm{g}$, respectively, for the modified portland cement, 2.94 and $4497 \mathrm{~cm}^{2} / \mathrm{g}$ for GGBFS, and 2.32 and $200,000 \mathrm{~cm}^{2} / \mathrm{g}$ for SF.

Natural sand and locally available crushed granite with a maximum particle size of $25 \mathrm{~mm}$ were used for fine and coarse aggregates, respectively. The specific gravity, water absorption, and fineness modulus are given in Table 3 .

\subsection{Mock-up Wall Specimens and Curing}

To simulate the primary containment-vessel of a nuclear reactor, wall specimens were prepared. The size of these wall specimens was $1200 \times 1000 \times 2000 \mathrm{~mm}$, as shown in Fig. 1. For vertical and horizontal reinforcements, deformed bars with a diameter of $35 \mathrm{~mm}$ were arranged at a spacing of $300 \mathrm{~mm}$ as a minimum configuration of wall reinforcement. Both ends of the walls were insulated using 50-mm-thick expanded polystyrene. The bottom of the walls had no insulation materials. To cure the wall specimens under isothermal ambient temperatures, three chambers were manufactured using 75-mm-thick sandwich panels, as shown in Fig. 2. Each curing chamber was equipped with an automatic constant-temperature control system. The average temperatures in the chambers were set to 5,20 , and $35^{\circ} \mathrm{C}$ to simulate cold weather (winter), reference (control laboratory) and hot weather (summer) conditions, respectively, because the three mixture proportions of concrete were determined considering different ambient temperatures in South Korea. After the wall formworks were set up in the chambers, the concrete was placed using a concrete pumping vehicle. The concretes were produced at a ready-mixed concrete plant using the mixture proportions given in Table 1. Because the mock-up tests were carried out during cold weather, the minimum concrete temperatures at time of placement and mixing were maintained above 7 and $10{ }^{\circ} \mathrm{C}$, respectively, in accordance with the ACI 306 report (2010). Immediately after casting, the specimens were covered with

Table 2 Chemical composition of cementitious materials (\% by mass).

\begin{tabular}{c|c|c|c|c|c|c|c|c|c|c}
\hline Materials & $\mathrm{SiO}_{2}$ & $\mathrm{Al}_{2} \mathrm{O}_{3}$ & $\mathrm{Fe}_{2} \mathrm{O}_{3}$ & $\mathrm{CaO}$ & $\mathrm{MgO}$ & $\mathrm{K}_{2} \mathrm{O}$ & $\mathrm{Na}_{2} \mathrm{O}$ & $\mathrm{TiO}_{2}$ & $\mathrm{SO}_{3}$ & $\mathrm{LOI}^{*}$ \\
\hline \hline $\begin{array}{c}\text { Modified } \\
\text { cement }\end{array}$ & 23.30 & 3.85 & 3.83 & 63.4 & 1.24 & 1.47 & 0.15 & 0.33 & 2.01 & 0.42 \\
\hline $\mathrm{SF}$ & 98.94 & 0.30 & 0.08 & 0.12 & 0.04 & 0.13 & 0.05 & - & 0.28 & 0.06 \\
\hline GGBFS & 33.18 & 14.07 & 0.51 & 44.6 & 4.31 & 0.45 & 0.24 & 0.55 & 1.36 & 0.73 \\
\hline
\end{tabular}

* Loss on ignition. 
Table 3 Physical properties of aggregates.

\begin{tabular}{c|c|c|c|c|c}
\hline Type & Maximum size $(\mathrm{mm})$ & Bulk density $\left(\mathrm{kg} / \mathrm{m}^{3}\right)$ & Specific gravity & Water absorption (\%) & Fineness modulus \\
\hline \hline Coarse aggregates & 25 & 1.557 & 2.59 & 0.78 & 6.64 \\
\hline Fine aggregates & 5 & 1.668 & 2.56 & 1.34 & 2.80 \\
\hline
\end{tabular}

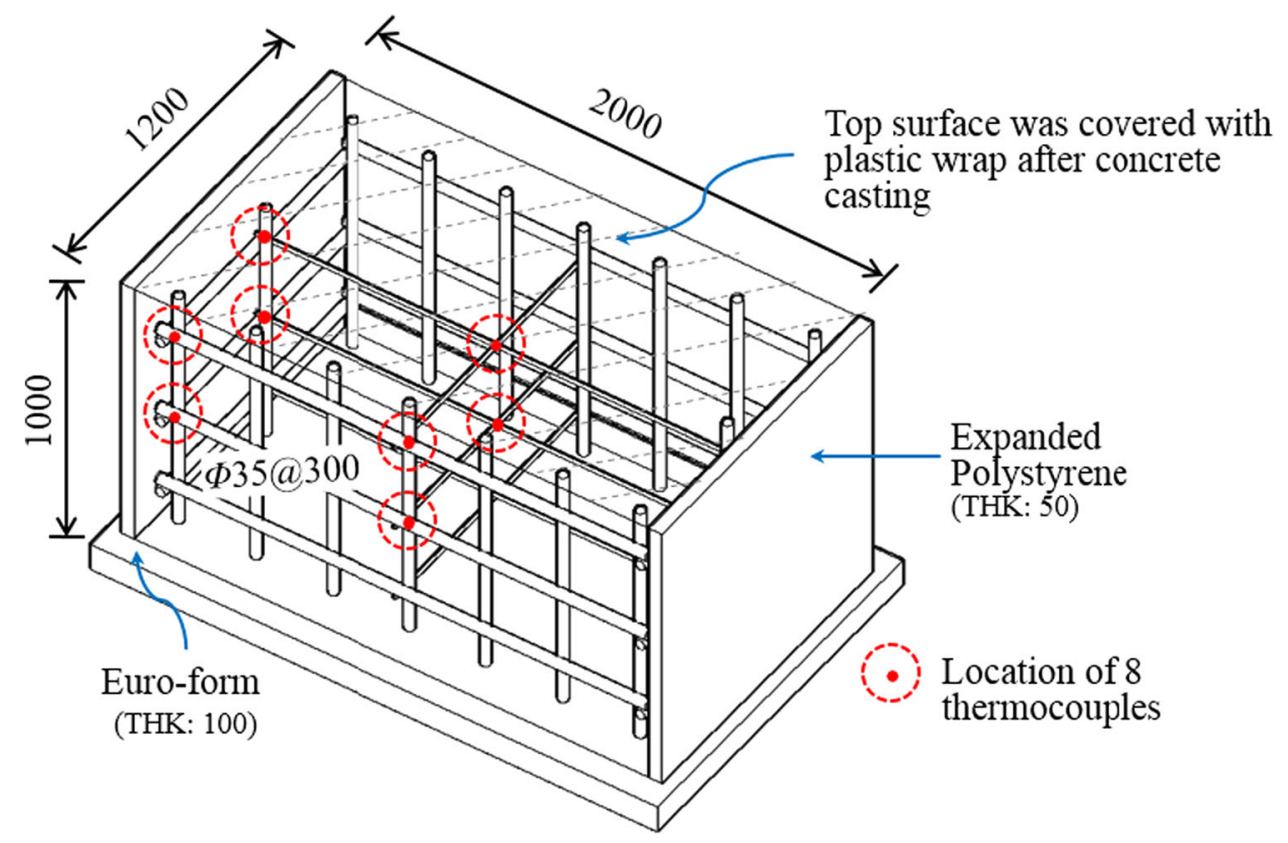

Fig. 1 Details of mock-up wall specimens and location of thermocouples (All dimensions are in $\mathrm{mm}$ ).

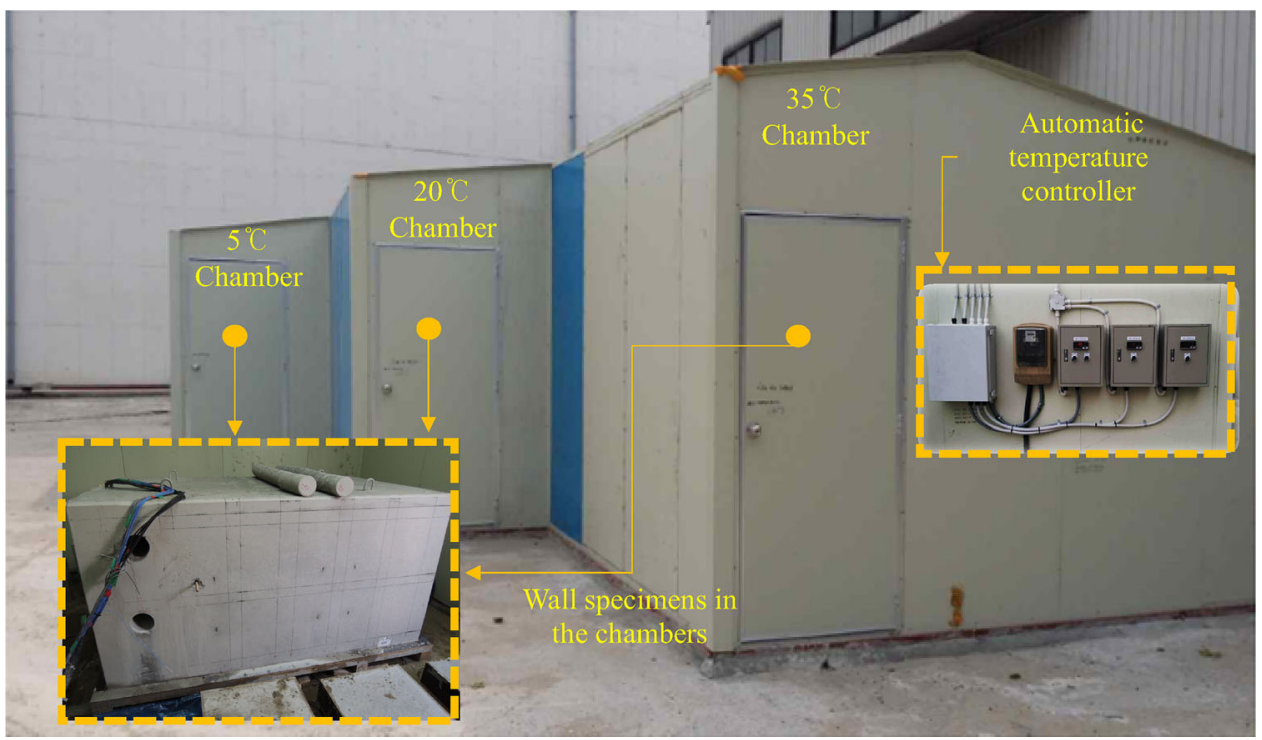

Fig. 2 Curing chambers equipped with constant-temperature control systems.

a vinyl chloride sheet to control evaporation. The wall specimens were continuously cured in the chambers under the previously set ambient temperature conditions. For comparison with the field-cured cylinder strength, $100 \times 200 \mathrm{~mm}$ cylinders molded from each concrete mixture were simultaneously cured with the wall specimens at the same ambient temperatures. The cylinders and the wall specimen cured under the cold condition were stripped out at an age of 3 days, whereas the others cured under the reference or hot condition were stripped out at 1 day.

\subsection{Testing}

Temperatures were monitored using thermocouples within the chambers and at eight different locations for the wall specimens, including the center and near surface regions, as shown in Fig. 1. Temperature data were recorded using a 
data logger at 20-min intervals to the end of the first day, and every $2 \mathrm{~h}$ thereafter. To evaluate setting times by penetration resistance and determine the apparent activation energy of the prepared concrete mixture, fresh mortar was extracted from each concrete mix using a 4.75-mm sieve. The mortars were simultaneously cured with each wall specimen at the same ambient temperatures. The penetration resistance testing to determine the setting time of the concrete was conducted in accordance with ASTM C403/C403 M (2011). The testing required to experimentally determine the apparent activation energy for the hardening phase was performed using 18 cubes with $50-\mathrm{mm}$ dimensions and cured at three temperatures $\left(5,20\right.$, and $\left.35^{\circ} \mathrm{C}\right)$, in accordance with ASTM C1074 (2011). To measure the in situ strength of the concrete in the walls, cores with a diameter of $100 \mathrm{~mm}$ were drilled at different locations with different hydration heat histories, as shown in Fig. 3. All cores were drilled horizontally. Cores were not drilled at the bottom regions of the walls because it was difficult to install a core machine there. The extraction was carefully carried out by experienced operators to minimize drilling damage. The cores were classified into four groups according to their drilling locations as follows (Fig. 3): inner surface portion at top region [top surface (TS)], central portion at top region [top center (TC)], inner surface portion at middle region [middle surface (MS)], and central portion at middle region [middle center (MC)]. The cores, which did not contain reinforcement, were cut to a length of $200 \mathrm{~mm}$ and tested in the same manner as standard cylinder specimens with the same dimension, in accordance with ASTM C42/C42 M (2011). The ends of the cores were ground to minimize an eccentricity. Immediately after the cores were drilled, the drilling water was wiped from their surface using dry towels. Measurements of the compressive strength of the cores were scheduled at the ages of $3,7,14,28,56$, and 91 days. Only 2 cores per location and testing age were tested because of the size limitation of the mock-up walls.

The core strength is affected by aspect ratio and diameter of the cores, presence of embedded reinforcement, and disturbance owing to drilling (Uva et al. 2013). Thus, the compressive strength $\left(f_{\text {core }}\right)$ of the cores was corrected using a single relationship specified in ACI 214.4R-10 (2010), as follows:

$$
S=F_{H / D} F_{\text {dia }} F_{m c} F_{d} f_{\text {core }}
$$

where $S$ is the corrected strength of concrete, and $F_{H / D}, F_{\text {dia }}$, $F_{m c}$, and $F_{d}$ are correction factors to account for the slenderness, diameter, moisture content, and damage to the surface of the core. The correction factors for the current cores, $F_{H / D}$, $F_{d i a}$, and $F_{m c}$ are calculated to be 1.0 and $F_{d}$ is 1.06 .

Because the mock-up walls were not subjected to any loads, no cracking owing to external loads existed in the cores. Furthermore, apparent damage or cracking owing to drilling was not observed in the surface of the cores, as shown in Fig. 4.

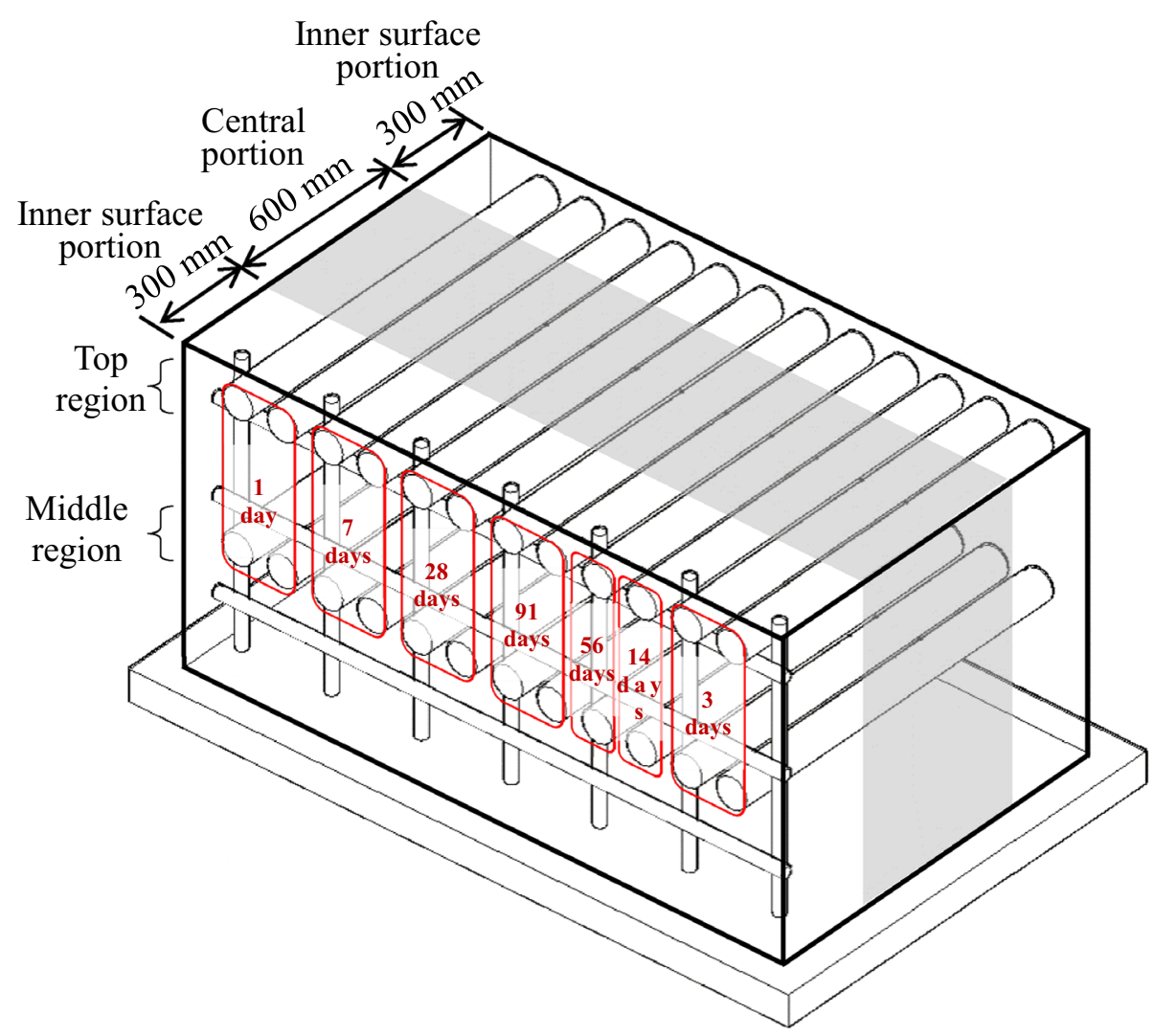

Fig. 3 Core drilling locations in wall specimens at different testing ages. 


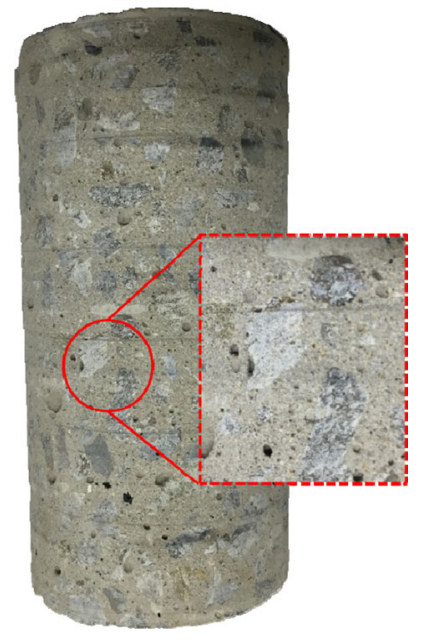

Fig. 4 Typical surface state of core samples.

\section{Test Results and Discussion}

\subsection{Temperature Rise}

The temperature rise profiles of the concrete resulting from the hydration of the cementitious materials are shown in Fig. 5. The ambient temperature profile of each chamber is also plotted on the same figure. As expected, peak temperature was higher at the central portion of the wall than at its inner surface. The highest temperature was recorded in the middle-center region. The differences between the peak temperatures at the center and inner surface regions tended to decrease with an increase in the ambient curing temperature. The peak temperature measured in the middle center was higher for $\mathrm{S} 5$ wall cured under $5{ }^{\circ} \mathrm{C}$ than for the other walls, whereas the peak temperature measured in the surface was higher for $\mathrm{G} 65 \mathrm{~S} 5$ wall cured under $35{ }^{\circ} \mathrm{C}$ than the other walls. A higher ambient curing temperature resulted in the hotter surface of the wall. This implies that the difference of the peak temperatures between the center and inner surface regions is more dependent on the ambient curing temperature than the mixture proportions used in the present study. It is also interesting that a greater slope at the ascending branch of the temperature rise curve was observed at the central portion compared to the surface portion under the cold curing condition, whereas this trend was reversed under the hot curing condition. The times required to reach the peak temperature at the central portion were $1.5,2$, and 2 days under the cold, reference, and hot conditions, respectively, showing the potential for a faster strength development with the S5 mixture under the cold temperature than the G65S5 mixture under the hot temperature. This was because the addition of GGBFS reduced the rate of hydration reactions of the cementitious materials. On the other hand, the rate of the temperature drop after reaching the peak increased with a decrease in the ambient curing temperature.

It is commonly known that the potential maximum heat production of SCMs is lower than that of portland cement (Nili and Salehi 2010). As a result, using SCMs as cement replacements in concrete reduces the temperature rise by reducing the cement content per a unit volume. Figure 5 also

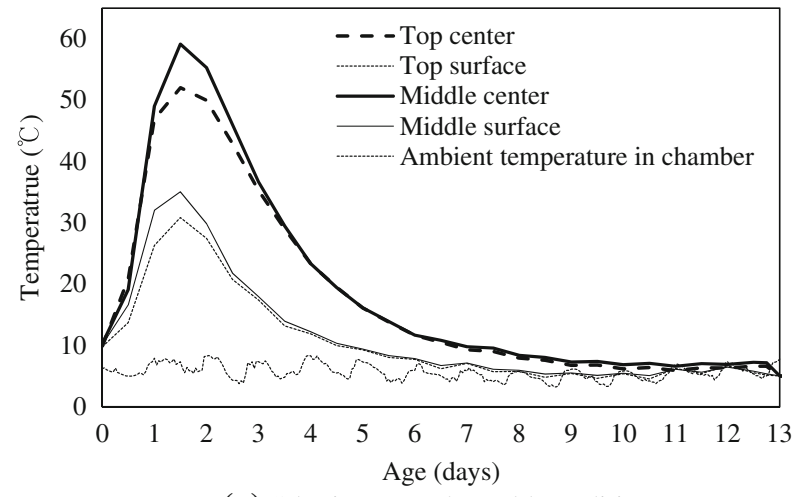

(a) S5 mixture under cold condition

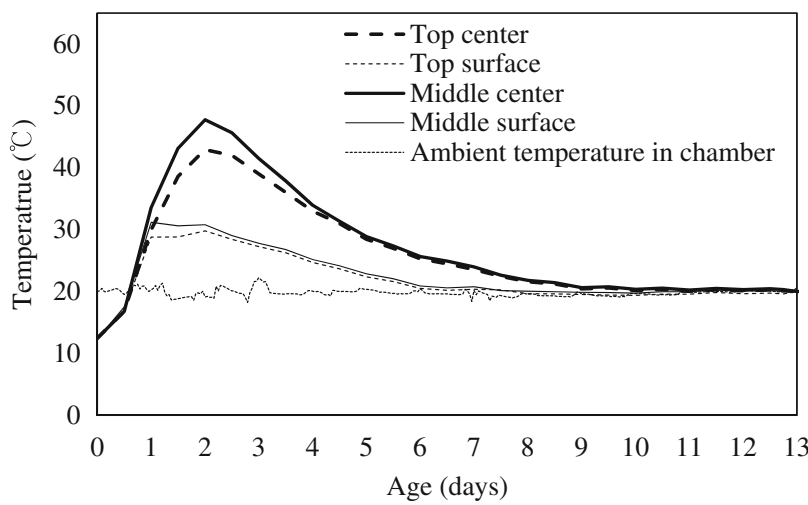

(b) G50 mixture under reference condition

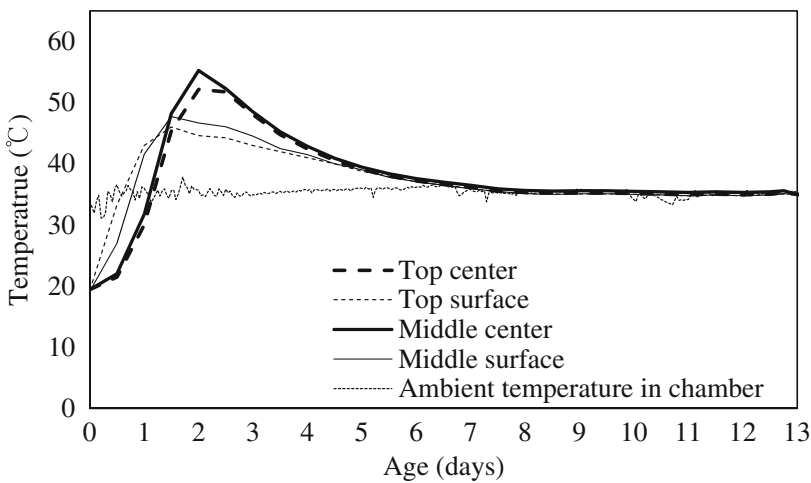

(c) G65S5 mixture under hot condition

Fig. 5 Temperature rise profile for each concrete wall.

clearly demonstrates that the peak temperature recorded in the middle-center region of the G50 wall was lower than that of the S5 wall, even though the G50 mixture was cured under a higher ambient temperature than the $\mathrm{S} 5$ mixture. The peak temperature of the G65S5 wall was higher than that of the G50 wall, even though a higher amount of SCM was used in the G65S5 concrete than in the G50 concrete. The heat production rate at an early age in cement paste commonly increases with an increase in the curing temperature (Zákoutský et al. 2012), which results in a higher cumulative heat production at an early age. The $35^{\circ} \mathrm{C}$ ambient temperature increased the rate of hydration to compensate for the reduced portland cement content. This implies that a higher curing temperature produces a higher temperature rise in concrete but leads to a lower differential between the core and surface of concrete element. 


\subsection{Activation Energy Until Final Setting Time}

Figure 6 shows the setting behavior of the tested mixtures and the fitting curves determined from each dataset. The penetration resistance versus time of each concrete mixture significantly depended on the ambient curing temperature and the addition of GGBFS. The differences in the setting times of the concrete mixtures decreased with an increase in the ambient curing temperature. As shown in Table 4, the G50 and G65S5 mixtures showed longer final setting times than the S5 mixture by 5.3 and $8.2 \mathrm{~h}$ under the cold temperature condition, 3.4 and $5.4 \mathrm{~h}$ under the reference temperature condition, and 1.0 and $1.5 \mathrm{~h}$ under the hot temperature condition, respectively. This indicates that the delay in final setting of concrete owing to the addition of slag cemnet is more notable with a decrease in the ambient curing temperature. The apparent activation energy $\left(E_{s}\right)$ until the final setting time was calculated from the Arrhenius plot using the inverse of the final setting time as a rate constant. The obtained values for $E_{s}$ were 22,700, 24,800, and $26,100 \mathrm{~J} / \mathrm{mol}$ for the S5, G50 and G65S5 mixtures, respectively, as given in Table 4 . Overall, $E_{s}$ slightly increased with an increase in the addition of GGBFS.

\subsection{Initial Activation Energy at Start of Hardening Phase}

In general, the apparent activation energy is considered to be a key parameter in the maturity function using the equivalent age, because it describes the effect of the temperature on the rate of the strength development of the

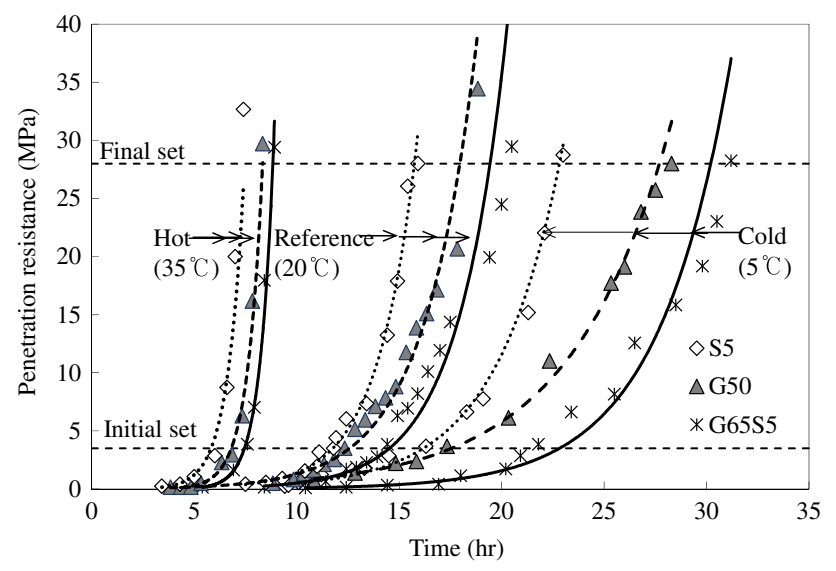

Fig. 6 Setting behavior of concrete mixtures according to curing temperature. concrete after final setting. Using a graph with the reciprocal of compressive strength of mortars cured under three different temperatures of 5,20 , and $35^{\circ} \mathrm{C}$ and the reciprocal of age, the rate constant $\left(k_{t}\right)$ of each concrete mixture was determined (see Table 4), in accordance with ASTM C1074 (2011). At the same curing temperature, the $k_{t}$ values determined at the start of the hardening phase were lower in the G50 and G65S5 mixtures than in the S5 mixture, indicating that $k_{t}$ decreases with an increase in the addition of GGBFS, as shown in Fig. 7. The temperature dependence of $k_{t}$ showed a nonlinear variation rather than a linear relationship, regardless of the SCM addition. Consequently, the $k_{t}$ values for each concrete were fitted using the Arrhenius function.

The initial apparent activation energy $\left(E_{i}\right)$ values calculated from the Arrhenius plot of the natural logarithm of the $k_{t}$ values versus the inverse of absolute temperature were $42,200,54,700$, and $68,900 \mathrm{~J} / \mathrm{mol}$ for the S5, G50 and G65S5 mixtures, respectively, as given in Table 4. These values for such mixtures were higher by $1.8,2.2$, and 2.6 times, respectively, than the values of $E_{s}$. This implies that the temperature sensitivity of the strength development after final setting is more than that of setting time. The apparent activation energy was not a constant value, because it depends on the type of cement, the type and dosage of the SCMs, and the $w / \mathrm{cm}$. In general, the values of $E_{i}$ for normalstrength OPC concrete without SCMs have been reported to be between 40,000 and 45,000 J/mol (ASTM 2011). The values of $E_{i}$ for the current concrete mixtures exceeded the general range for OPC, showing that the $E_{i}$ value tended to increase with an increase in the dosage level of GGBFS. These higher values of $E_{i}$ indicates that strength development of concrete with GGBFS would be more sensitive to temperature than OPC concrete.

\subsection{8-Day Compressive Strength $\left(S_{28}\right)$}

Figure 8 shows comparisons of the field-cured cylinder strengths and core strengths of the concrete mixtures at an age of 28 days. The strength of the concrete mixtures measured using $100 \times 200 \mathrm{~mm}$ cylinders were close to the design strength of $55 \mathrm{MPa}$. The strength of the S5 mixture at $5{ }^{\circ} \mathrm{C}$ was approximately $10 \%$ higher than that of the G50 mixture cured at $20^{\circ} \mathrm{C}$. The G65S5 mixture cured at $35^{\circ} \mathrm{C}$ had a 28 -day strength similar to the G50 mixture. Compared with the field-cured cylinder strength, a higher 28-day core strength was commonly observed. The average ratios between core strengths and cylinder strengths were

Table 4 Characteristics of concrete mixtures.

\begin{tabular}{|c|c|c|c|c|c|c|c|c|c|c|c|}
\hline \multirow[t]{3}{*}{ Mixtures } & \multicolumn{6}{|c|}{ Setting time (hrs) } & \multirow[t]{3}{*}{$E_{S}(\mathrm{~J} / \mathrm{mol})$} & \multirow[t]{3}{*}{$E_{i}(\mathrm{~J} / \mathrm{mol})$} & \multirow{2}{*}{\multicolumn{3}{|c|}{$k_{t}$ (1/days) }} \\
\hline & \multicolumn{2}{|c|}{$5{ }^{\circ} \mathrm{C}$} & \multicolumn{2}{|c|}{$20{ }^{\circ} \mathrm{C}$} & \multicolumn{2}{|c|}{$35^{\circ} \mathrm{C}$} & & & & & \\
\hline & Initial & Final & Initial & Final & Initial & Final & & & $5^{\circ} \mathrm{C}$ & $20^{\circ} \mathrm{C}$ & $35^{\circ} \mathrm{C}$ \\
\hline S5 & 16.30 & 23.00 & 10.80 & 14.92 & 6.50 & 7.70 & 22,700 & 42,200 & 0.16 & 0.30 & 0.95 \\
\hline G50 & 17.34 & 28.30 & 12.34 & 18.37 & 7.42 & 8.57 & 24,800 & 54,700 & 0.07 & 0.18 & 0.72 \\
\hline G65S5 & 21.80 & 31.20 & 15.20 & 20.30 & 8.00 & 8.90 & 26,100 & 68,900 & 0.05 & 0.15 & 0.70 \\
\hline
\end{tabular}


1.15 and 1.19 at the top and middle regions, respectively, for the S5 wall, and 1.21 and 1.27 at those regions of the G50 wall. The 28-day core strength was slightly higher at the middle regions of the walls compared to the top regions, whereas the difference of the core strengths between the inner surface and center at each region was not significant. The ratios between the core strength and cylinder strength for the G50 wall were higher than those for the S5 wall, even though the temperature difference between the wall core and atmosphere owing the hydration heat was greater in the S5 wall than in the G50 wall. This may be attributed to the higher value of $E_{i}$ for G50 mixture. In addition, the GGBFS has more temperature sensitivity than SF, which showed that, under a hot temperature of $30-50{ }^{\circ} \mathrm{C}$, a higher strength could be obtained in concrete with GGBFS than in concrete with SF at the same $w / \mathrm{cm}$ (Lee et al. 2013). The average ratios between the core strength and cylinder strengths were lower for the G65S5 wall than those of the other walls.

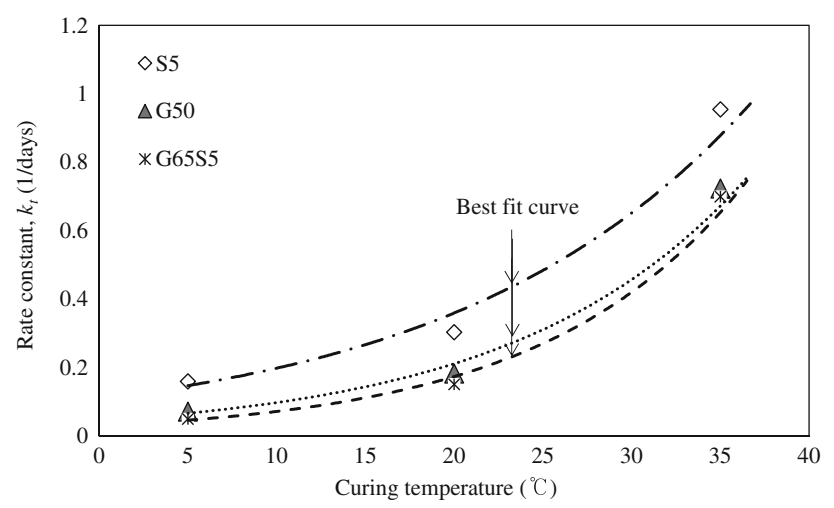

Fig. 7 Rate constant during initial hardening phase of concrete.

\subsection{Comparison of Compressive Strength Development}

Table 5 gives the average strength measured from the cores and field-cured cylinders at different ages. For the S5 mixture cured under the cold condition, the core strength was higher than the cylinder strength until an age of 28 days, beyond which a higher strength was obtained in the cylinder, showing the crossover behavior, that is, higher early-age temperatures result in higher early strength and lower longterm strength. As shown in Fig. 5, the temperature at the center portion of the $\mathrm{S} 5$ wall owing to the hydration heat was above $20{ }^{\circ} \mathrm{C}$ until an age of 4 days, and then remained slightly higher than the ambient temperature. The walls experienced higher early-age temperatures than the cylinders and concrete S5 is susceptible to the crossover effect. This indicates that a higher core strength was obtained until an age of 56 days, compared to the cylinder strength, and the core strength was also higher at the wall center than at its inner surface. It is noted that the threshold age for the crossover effect is commonly observed between 7 and 14 days in OPC concrete (Carino and Tank 1992; Neville 1995). However, the present S5 mixture showed a longer threshold age of around 56 days. The chemical composition of the modified cement used for the present mixture was close to that of moderate heat cement, giving lower $\mathrm{C}_{3} \mathrm{~S}$ and $\mathrm{C}_{3} \mathrm{~A}$ contents than OPC. The reduced $\mathrm{C}_{3} \mathrm{~S}$ and $\mathrm{C}_{3} \mathrm{~A}$ contents in the modified cement were unfavorable to strength development at an early age. Furthermore, the period when the temperature was maintained above $10{ }^{\circ} \mathrm{C}$ at the center region of a wall was the first 7 days only. For these reasons, a late threshold age for the crossover effect was obtained in the S5 mixture. The strength gain of the cores beyond 28 days was insignificant, revealing that the core strength ratios between 91 days and 28 days did not exceed 1.05. This implies that the high early-age curing temperature caused by the hydration heat reduced long-term strength gain of concrete S5. No

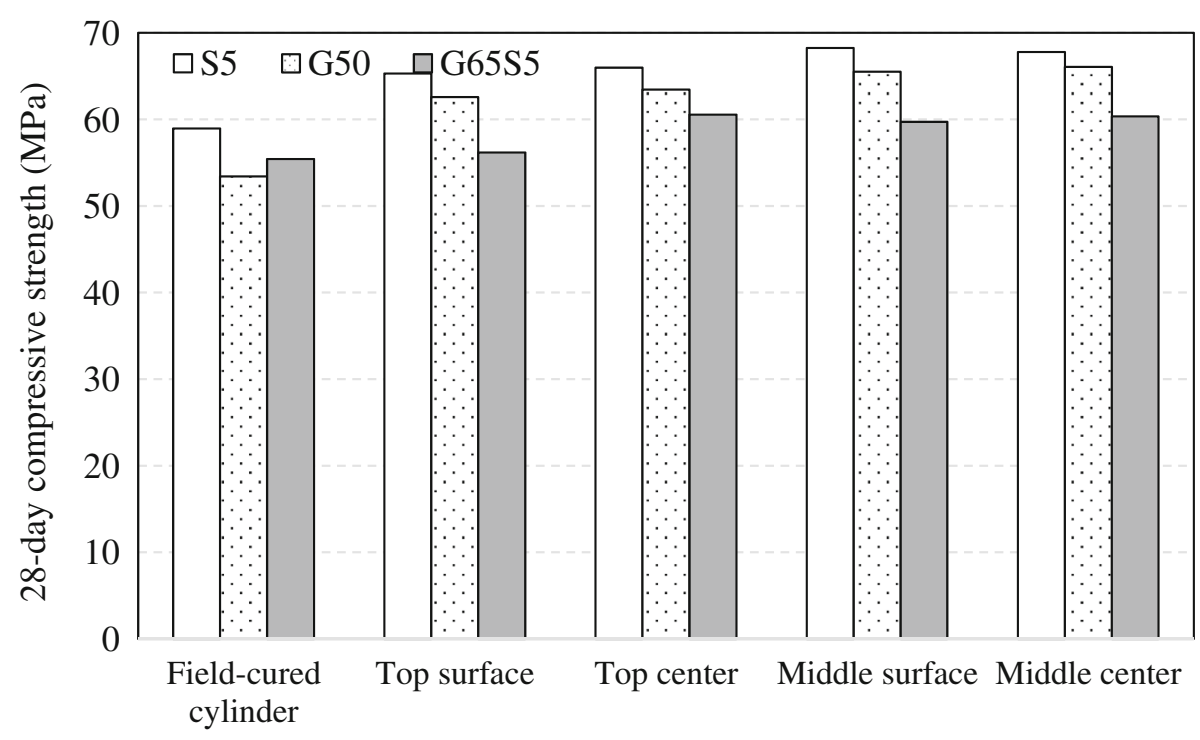

Core location in walls

Fig. 8 Comparisons of field-cured cylinder and core strengths at age of 28 days. 
Table 5 Compressive strength development of concrete mixtures.

\begin{tabular}{|c|c|c|c|c|c|c|c|c|}
\hline \multirow[t]{2}{*}{ Mixture } & \multirow{2}{*}{\multicolumn{2}{|c|}{ Specimens }} & \multicolumn{6}{|c|}{ Compressive strength (MPa) at different ages (days) } \\
\hline & & & 3 & 7 & 14 & 28 & 56 & 91 \\
\hline \multirow[t]{5}{*}{ S5 } & \multicolumn{2}{|c|}{ Field-cured cylinder } & 21.5 & 37.9 & 50.9 & 58.9 & 67.5 & 75.8 \\
\hline & \multirow{4}{*}{$\begin{array}{c}\text { Core (location } \\
\text { drilled from } \\
\text { walls) }\end{array}$} & Top surface & 32.4 & 49.2 & 61.9 & 65.3 & 65.5 & 66.7 \\
\hline & & Top center & 34.4 & 48.5 & 62.8 & 66.0 & 66.6 & 67.0 \\
\hline & & Middle surface & 36.6 & 51.4 & 64.7 & 68.3 & 68.3 & 69.7 \\
\hline & & Middle center & 44.9 & 52.3 & 61.4 & 67.8 & 69.8 & 71.0 \\
\hline \multirow[t]{5}{*}{ G50 } & \multicolumn{2}{|c|}{ Field-cured cylinder } & 18.4 & 37.5 & 45.5 & 53.4 & 55.4 & 58.9 \\
\hline & \multirow{4}{*}{$\begin{array}{c}\text { Core (location } \\
\text { drilled from } \\
\text { walls) }\end{array}$} & Top surface & 27.8 & 44.2 & 50.2 & 62.6 & 63.4 & 65.4 \\
\hline & & Top center & 35.9 & 50.0 & 56.0 & 63.5 & 64.6 & 65.7 \\
\hline & & Middle surface & 29.4 & 43.7 & 56.4 & 65.5 & 65.5 & 67.1 \\
\hline & & Middle center & 33.6 & 53.0 & 56.2 & 66.0 & 67.0 & 67.6 \\
\hline \multirow[t]{5}{*}{ G65S5 } & \multicolumn{2}{|c|}{ Field-cured cylinder } & 30.7 & 45.3 & 52.2 & 55.4 & 55.1 & 58.3 \\
\hline & \multirow{4}{*}{$\begin{array}{c}\text { Core (location } \\
\text { drilled from } \\
\text { walls) }\end{array}$} & Top surface & 32.7 & 48.4 & 54.5 & 56.2 & 56.8 & 58.3 \\
\hline & & Top center & 43.3 & 54.9 & 57.0 & 60.6 & 58.3 & 60.6 \\
\hline & & Middle surface & 35.8 & 48.3 & 55.8 & 59.7 & 61.3 & 62.8 \\
\hline & & Middle center & 41.3 & 55.6 & 56.0 & 60.4 & 63.3 & 63.7 \\
\hline
\end{tabular}

crossover effect was observed in either the G50 or the G65S mixture. For the G50 mixture, which was stored at an ambient temperature of $20^{\circ} \mathrm{C}$, higher core strengths compared to cylinder strengths were obtained throughout the testing ages, showing the highest strength for the core drilled from the middle-center region of the wall, as given in Table 5. The G65S5 mixture, which was stored at $35^{\circ} \mathrm{C}$, showed smaller differences between the core and cylinder strengths, compared with the other mixtures.

\section{Comparisons of Maturity Functions and Experiments}

\subsection{Review of Existing Models}

Considering temperature variation by the heat of hydration in mass concrete or the change of external environment, Kim et al. (2002a) proposed a modified strength-maturity relationship for estimating strength development of concrete, as summarized in Table 6. Their modified maturity function assumed that the value of $E_{i}$ is constant with aging because the activation energy can be regarded to be the characteristic property of concrete, whereas the limiting strength $\left(S_{u}\right)$ is a function of age and temperature under variable curing temperature. In the maturity function, the parameters were based on regression analysis of test data. However, the value of $S_{u}$ under variable temperature was not clearly identified, which would lead to additional hard task to obtain straightforwardly the strength development at a specified age.

Pinto and Schindler (2010) proposed an extended maturity approach to unify the distinctly different temperature sensitivities before setting and during the hardening period of concrete, based on the Arrhenius maturity function. The effect of different activation energies on the strength-maturity relationship was taken into account, as summarized in Table 6 . This maturity approach also demonstrated that the setting behavior needs to be taken into account in the strength-maturity relationship in order to improve the overall strength estimation of concrete at all ages. Hence, different activation energy values before and after the final setting of concrete were used in calculating equivalent age at the reference temperature. The offset time function $\left(t_{s r}\right)$ was introduced to account for the effect of temperature on the setting time of the concrete. However, there are insufficient data for verification of the Pinto and Schindler model for estimating strength gain under variable temperature conditions.

Yang (2014) proposed a modification for the strength-maturity relationship proposed by Carino and Tank (1992) in order to explain that the maturity is related to the relative strength rather than the absolute strength. The maturity function computes the equivalent age $\left(t_{e}\right)$ at the reference temperature $\left(T_{r}\right)$, including the setting and hardening phases. Because the offset time $\left(t_{0 r}\right)$ at $T_{r}$ is related to the setting behavior of concrete, the offset time $\left(t_{0}\right)$ at a given temperature was assumed to be equal to the final setting time $\left(t_{s}\right)$ of concrete at that temperature. This maturity function considered that during the hardening phase, increments of equivalent age are proportional to the affinity ratio of the rate constants using $E_{a}$, whereas the offset time at the setting phase is inversely proportional to the affinity ratio determined using $E_{s}$, because a higher temperature would result in a shorter setting time. Furthermore, the temperature-dependent hydration reaction also affects the value of the $E_{a}$ at the hardening phase. Byfors (1980) showed that $E_{a}$ decreases sharply beyond a certain age 
Table 6 Summary of previous models for strength-maturity relationship.

\begin{tabular}{|c|c|}
\hline Researcher & Formulation of the relationship \\
\hline Kim et al. (2002a) & 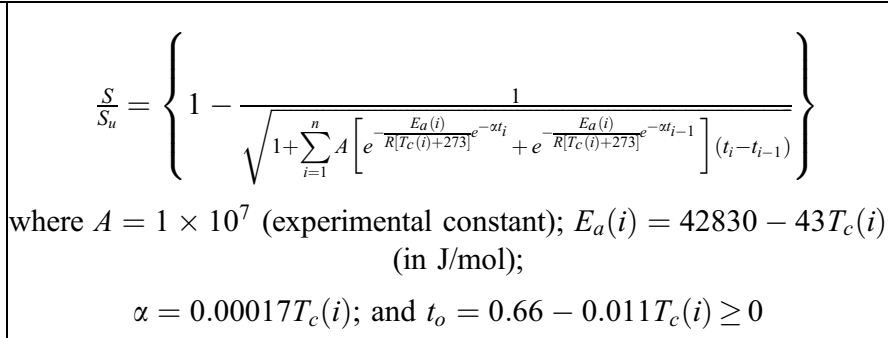 \\
\hline Pinto and Schindler (2010) & $\begin{array}{c}\frac{S}{S_{u}}=\frac{k_{r}\left(t_{e}^{*}-t_{s r}\right)}{1+k_{r}\left(t_{e}^{*}-t_{s r}\right)} \\
\text { where } t_{s r}=t_{s} \exp \left[-\frac{E_{s}}{R}\left(\frac{1}{T_{c}(i)+273}-\frac{1}{T_{r}+273}\right)\right] ; \text { and } \\
t_{e}^{*}=\sum_{0}^{t_{s r}} \exp \left[-\frac{E_{s}}{R}\left(\frac{1}{T_{c}(i)+273}-\frac{1}{T_{r}+273}\right)\right] t_{i}+ \\
\sum_{0}^{t} \exp \left[-\frac{E_{i}}{R}\left(\frac{1}{T_{c}(i)+273}-\frac{1}{T_{r}+273}\right)\right] t_{i}\end{array}$ \\
\hline Yang (2014) & $\begin{array}{c}\frac{S}{S_{28}}=\beta_{1} \frac{k_{r}\left(t_{e}-t_{o r}\right)}{1+k_{r}\left(t_{e}-t_{o r}\right)} \\
\text { where } \beta_{1}=\frac{S_{u}}{S_{28}}=1+\frac{1}{k_{r} \cdot 28} ; k_{T}=k_{r} \exp \left[-\frac{E_{a}(i)}{R}\left(\frac{1}{T_{c}(i)+273}-\frac{1}{T_{r}+273}\right)\right] ; \\
t_{o r}=t_{s r} \exp \left[-\frac{E_{s}}{R}\left(\frac{1}{T_{c}(i)+273}-\frac{1}{T_{r}+273}\right)\right] ; \\
t_{e}=\sum_{0}^{t_{s r}} \exp \left[-\frac{E_{s}}{R}\left(\frac{1}{T_{c}(i)+273}-\frac{1}{T_{r}+273}\right)\right] \Delta t_{i} \\
+\sum_{t_{s r}}^{3} \exp \left[-\frac{E_{a}(i)}{R}\left(\frac{1}{T_{c}(i)+273}-\frac{1}{T_{r}+273}\right)\right] \Delta t_{i}+ \\
\sum_{3}^{t} \exp \left[-\frac{E_{a}(i)}{R}\left(\frac{1}{T_{A 3}+273}-\frac{1}{T_{r}+273}\right)\right] \Delta t_{i} \\
S_{28}=\left[\left(\frac{T_{A 3}}{T_{r}}\right)^{2}(w / c m)^{4}+0.97\right]\left(S_{28}\right)_{T_{r}} ; \text { and } \\
E_{a}(i)=E_{i} \cdot \exp \left(-0.00017 T_{c}(i) \cdot t\right)\end{array}$ \\
\hline
\end{tabular}

that varies with curing temperature. Therefore, $E_{a}$ somewhat depends on the curing temperature and age, which affects the value of equivalent age. However, the compressive strength development of concrete is insignificantly affected by the value of the apparent activation energy. For the three concrete mixtures tested, the estimates using the constant value of $E_{i}$ produced the approximately same strength-age curves as the estimates using the variable value $E_{a}$ given in Table 6 . Hence, the parameter $E_{a}$ in Yang's model needs to be replaced using the constant $E_{i}$ for simpler calculation process. Yang (2014) showed that the strength development of HSC is independent of the curing temperature after an early critical age, and 3 days can be selected as this critical age. Considering the temperature-dependence of the setting and hardening phases and the early-age curing temperature effect until the critical period, $t_{e}$ for HSC was calculated as the sum of three terms, as given in Table 6. To straightforwardly calculate the strength development at different ages, the relationship between $S_{28}$ and $\left(S_{28}\right)_{T_{r}}$ needs to be established for a given concrete. From the regression analysis of test data, Yang showed that the relationship between $S_{28}$ and $\left(S_{28}\right)_{T_{r}}$ is significantly affected by $w /$ $\mathrm{cm}$ and the temperature until the early age of 3 days as a critical factor to represent the whole temperature history.

\subsection{Comparisons with Test Results}

Figure 9 shows some comparisons of estimated strength based on strength-maturity relationships in Table 6 with strength gain of concrete mixtures measured by the fieldcured cylinders and cores drilled from the middle center regions of the walls. Table 7 shows the mean $\left(\gamma_{m}\right)$, standard deviation $\left(\gamma_{s}\right)$, and coefficient of variation $\left(\gamma_{v}\right)$ of the ratios $\left(\gamma=S_{\text {estimation }} / S_{\text {test }}\right)$ between estimated compressive strength of concrete and test results. In estimating the in situ strengths of walls using the reviewed maturity approaches, the temperature profile measured at each core location was used for the curing temperature. The ambient temperature of each chamber was also used for estimating the strength of fieldcured cylinders. For the models proposed by Pinto and Schindler (2010) and Yang (2014), the experimental values given in Table 4 were used for key parameters such as $t_{s r}, k_{r}$, $E_{i}$, and $E_{s}$. For the limiting strength in the models of Kim et al. and Pinto and Schindler, 91-day strength was used. The model proposed by Kim et al. (2002a) underestimated the strength gain of the S5 mixture stored at $5{ }^{\circ} \mathrm{C}$ but tended to overestimate the strength gain of the G50 and G65S5 mixtures. This overestimation was greater for cylinder specimens than for cores, as shown in Fig. 9. The estimates obtained from the Pinto and Schindler model (2010) were also lower than the measured strength gain of the S5 mixture, but were in good agreement with the strength gain of cores drilled from the G50 and G665S5 walls. However, the Pinto and Schindler model still overestimated the field-cured cylinder strength of the G50 and G665S5 mixtures. Furthermore, this model gave no strength gain of cores at an age 

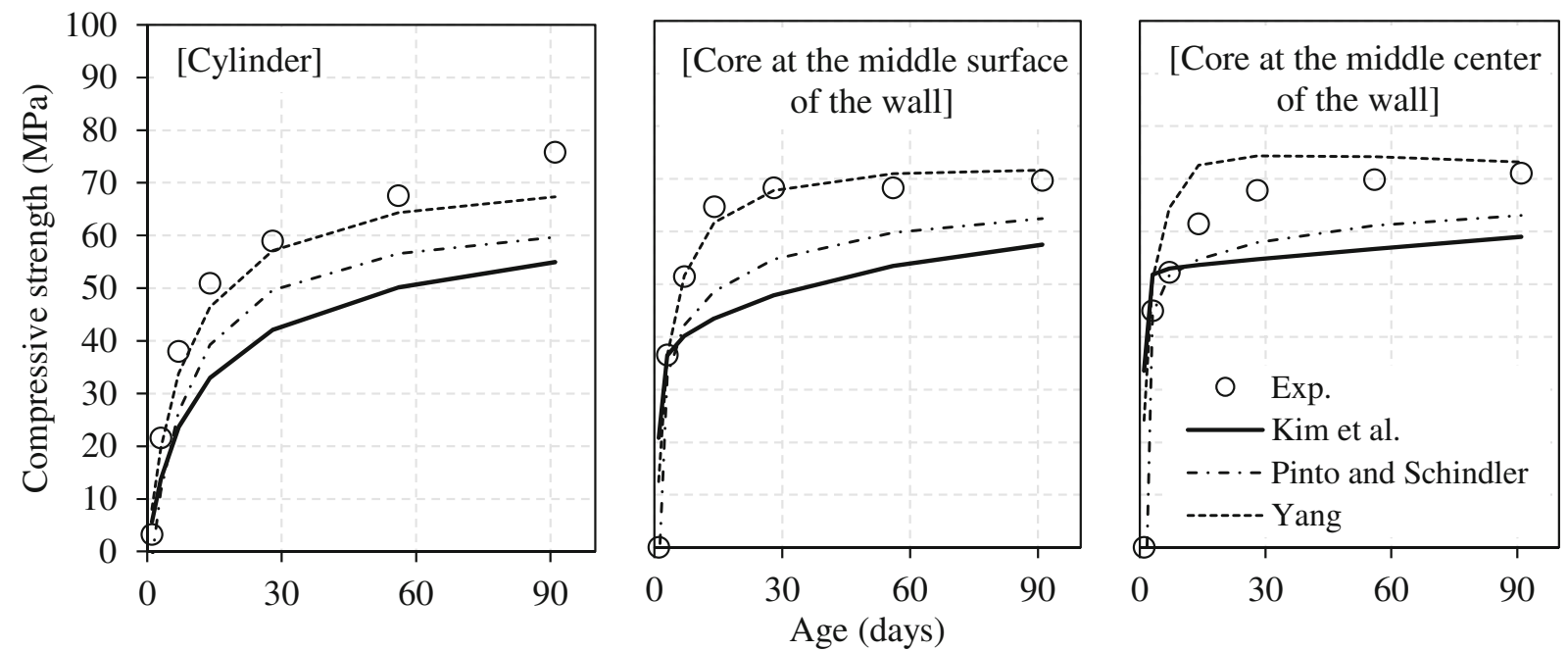

(a) S5 mixture under cold temperature condition
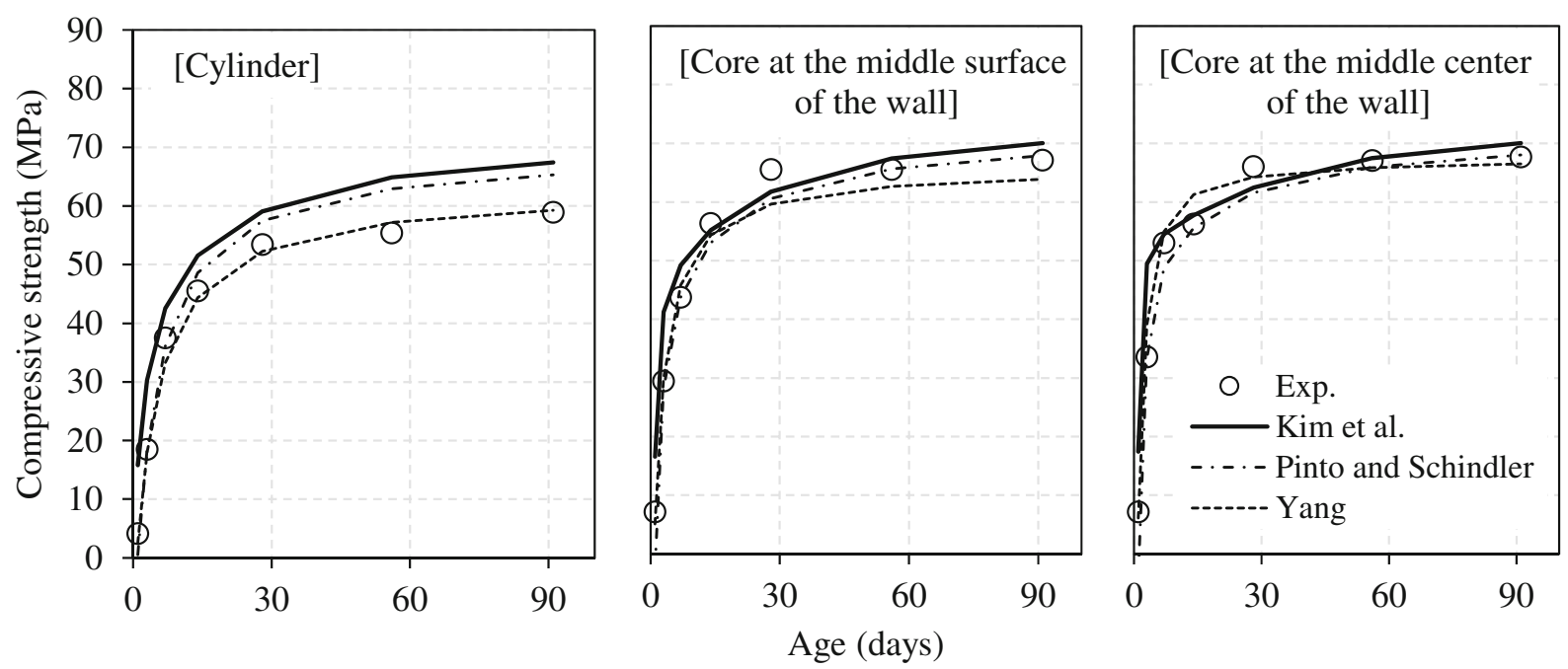

(b) G50 mixture under reference temperature condition
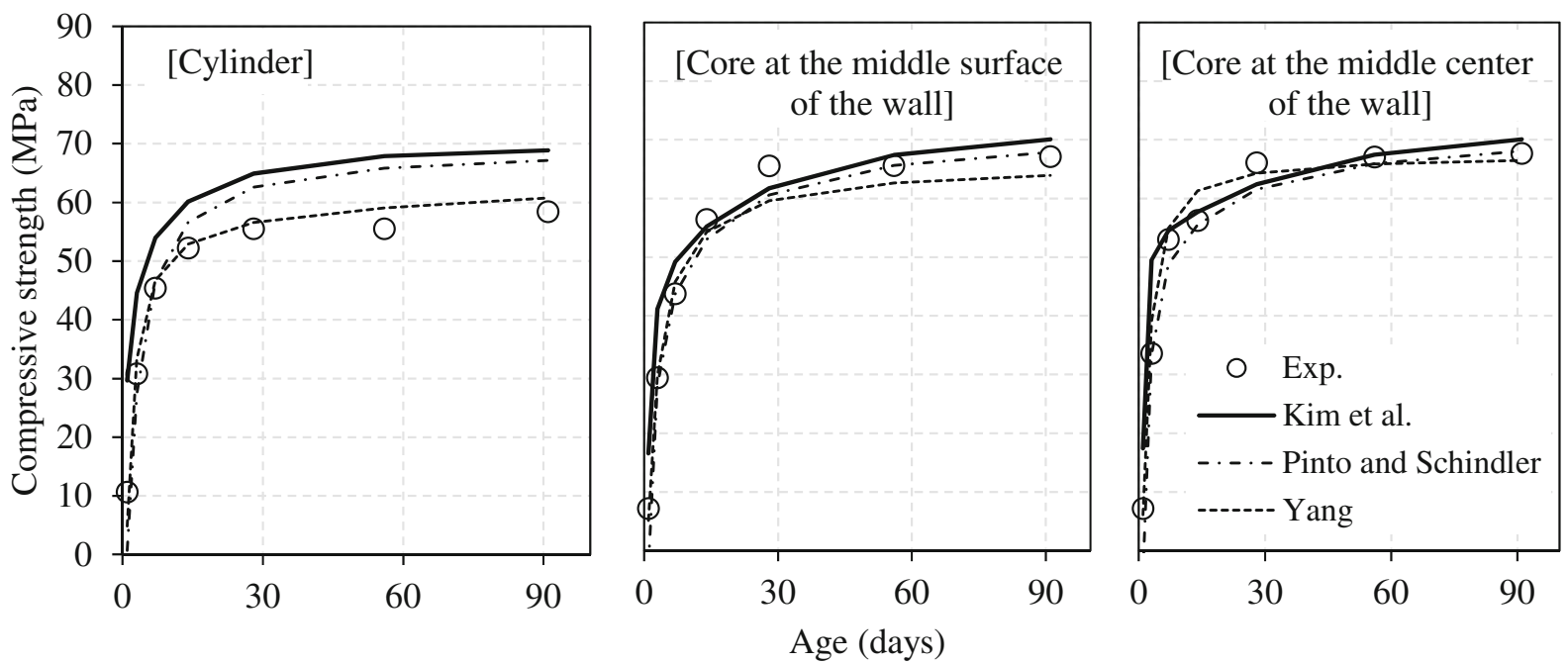

(c) G65S5 mixture under hot temperature condition

Fig. 9 Comparisons of measured strengths and estimates based on strength-maturity relationships given in Table 6 . 


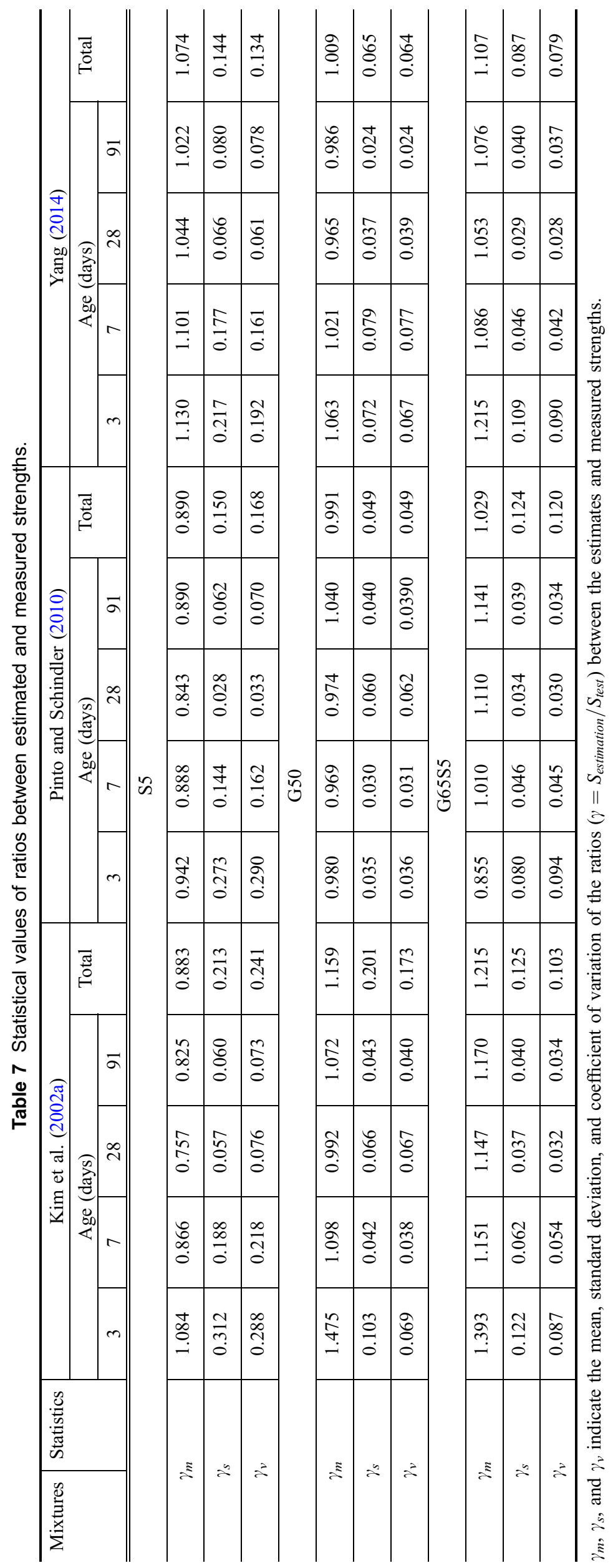


of 1 day. Pinto and Schindler model had lower values of $\gamma_{s}$ and $\gamma_{v}$ than Kim et al.'s model. The maturity approach proposed by Yang (2014) tended to overestimate the early strength until the age of 3 days for the S5 mixture and the G65S5 mixture, beyond which the overestimation gradually diminished. For the estimates based on Yang's model, no clear trend was observed for the differences in the $\gamma$ values between the cylinders and cores. For the three mixtures at different ages of $3,7,14,28,56$, and 91 days, the overall values of $\gamma_{m}, \gamma_{s}$, and $\gamma_{v}$ determined from the reviewed models were $1.057,0.219$, and 0.207 , respectively, for Kim et al., 0.979, 0.127, and 0.130 for Pinto and Schindler, and 1.058, 0.098, and 0.093 for Yang. This indicates that Yang's approach gives slightly more reliable estimates with less scatter, even at early ages.

\section{Conclusions}

To evaluate the effect of the hydration heat on the in situ strength development of three HSC mixtures in a massive wall stored under different ambient temperatures and examine the difference between field-cured cylinder strength and in situ strength measured from cores, 1200-mm thick mock-up walls were prepared and stored in approximately isothermal chambers at $5{ }^{\circ} \mathrm{C}$ (cold condition), $20{ }^{\circ} \mathrm{C}$ (reference condition), and $35^{\circ} \mathrm{C}$ (hot condition). The HSC mixture proportions specifically determined for use in nuclear facility structures were identified as S5 (with $5 \% \mathrm{SF}$ ) for storage under the cold condition, G50 (with $50 \%$ GGBFS) for storage under the reference condition, and G65S5 (with $65 \%$ GGBFS and $5 \%$ SF) for storage under the hot condition. The in situ compressive strength development in the mock-up walls measured from core samples was compared with estimated strength based on three strength-maturity relationship models, considering the temperature rise owing to the hydration heat. The following conclusions may be drawn from this study:

1. The G50 and G65S5 mixtures had longer final setting times than the S5 mixture, regardless of the curing temperature. The differences in the setting times of the concrete mixtures increased with a decrease in the ambient curing temperature.

2. The initial apparent activation energies at the hardening phase were higher by $1.8,2.2$, and 2.6 times for the S5, G50 and G65S5 mixtures, respectively, than the apparent activation energies until the final setting, indicating that the temperature sensitivity of the strength development is more than that of setting time.

3. The differences in the 28-day strengths between the field-cured cylinders and cores were higher for the G50 wall than for the S5 wall. Meanwhile, the 28-day strength measured by cores from the G65S5 wall was similar to that of the companion field-cured cylinders.

4. For the $\mathrm{S} 5$ mixture stored at $5{ }^{\circ} \mathrm{C}$, the core strength was commonly higher than the field-cured cylinder strength until an age of 28 days, beyond which a higher strength was obtained in the cylinders, showing the crossover effect. Furthermore, the core strength at an early age was higher at the central region of the wall than at its inner surface region due to greater temperature rise from heat of hydration.

5. For the G65S5 mixture, a strength gain of more than approximately $80 \%$ of design strength was achieved within the first 7 days, even for the field-cured strength. However, for the S5 mixtures stored at $5{ }^{\circ} \mathrm{C}$, the cylinder strength at 7 days failed to meet the $80 \%$ design strength level, whereas the core strengths achieved this value.

6. The strength-maturity model proposed by Yang provides better reliability in estimating in situ strength of concrete than that of Kim et al. and Pinto and Schindler, indicating that the internal curing effect owing to the hydration heat in a massive member needs to be considered to reasonably assess the early-age strength of concrete.

\section{Acknowledgments}

This work was supported by a Nuclear Research and Development program of the Korea Institute of Energy Technology Evaluation and Planning (KETEP) Grant funded by the Korea Government Ministry of Knowledge Economy (2011T100200161).

\section{Open Access}

This article is distributed under the terms of the Creative Commons Attribution 4.0 International License (http://creativecommons.org/licenses/by/4.0/), which permits unrestricted use, distribution, and reproduction in any medium, provided you give appropriate credit to the original author(s) and the source, provide a link to the Creative Commons license, and indicate if changes were made.

\section{References}

ACI Committee 214. (2010). Guide for obtaining cores and interpreting compressive strength results (ACI 214.4R-10). American Concrete Institute, Farmington Hills, Michigan, USA.

ACI Committee 306. (2010). Guide to cold weather concreting (ACI 306R-10). American Concrete Institute, Farmington Hills, Michigan, USA.

ASTM C42/C42 M, C150, C403/C403 M, C989, C1074. (2011). Annual Book of ASTM Standards, V. 4.02, ASTM International, West Conshohocken, PA. 2011.

Bamforth, P. B. (1980). In situ measurement of the effect of partial Portland cement replacement using either fly ash or ground granulated blast furnace slag on the performance of 
mass concrete. Proceeding Institution of Civil Engineers, 69(2), 777-800.

Bogue, R. H. (1955). Chemistry of portland cement. New York, NY: Reinhold Publisher.

Byfors, J. (1980). Plain concrete at early ages. CBI Research Report No. 3:80, Cement and Concrete Research.

Carino, N. J., \& Tank, R. C. (1992). Maturity function for concretes made with various cements and admixtures. $A C I$ Materials Journal, 89(2), 188-196.

Harris, D. W., Mohorovic, C. E., \& Dolen, T. P. (2000). Dynamic properties of mass concrete obtained from dam cores. ACI Materials Journal, 97(3), 290-296.

Haug, A. K., \& Jakobsen, B. (1990). In situ and design strength for concrete in offshore platforms. ACI SP 121-19 HighStrength Concrete. Second International Symposium, 369-397.

Hulshizer, A. J. (2001). The benefits of the maturity method for cold-weather concreting. Concrete International, 23(3), 68-72.

Kim, J. K., Han, S. J., \& Park, S. K. (2002a). Effect of temperature and aging on the mechanical properties of concrete. Part II. Prediction model. Cement and Concrete Research, 32(7), 1095-1100.

Kim, J. K., Han, S. H., \& Song, Y. C. (2002b). Effect of temperature and aging on the mechanical properties of concrete Part I. Experimental results. Cement and Concrete Research, 32(7), 1087-1094.

Lee, D. H., Kim, S. Y., Jeon, M. H., Kim, Y. H., \& Lee, K. H. (2013). Development of technology for the field application of blast-furnace slag powder concrete. Daejeon, Korea: Land \& Housing Institute.

Neville, A. M. (1995). Properties of concrete. New York: Addison Wesley Longman Limited.
Nili, M., \& Salehi, A. M. (2010). Assessing the effectiveness of pozzolans in massive high-strength concrete. Cement and Concrete Research, 24(11), 2108-2116.

Parsons, T. J., \& Naik, T. R. (1985). Early age concrete strength determination by maturity. Concrete International, 7(2), 37-43.

Pinto, R. C. A., \& Schindler, A. K. (2010). Unified modeling of setting and strength development. Cement and Concrete Research, 40(1), 58-65.

Pucinotti, R. (2013). Assessment of in situ characteristic concrete strength. Construction and Building Materials, 44, 63-73.

Schrader, E. (2007). Statistical acceptance criteria for strength of mass concrete. Concrete International, 29(6), 57-61.

Sofi, M., Mendis, P. A., \& Baweja, D. (2012). Estimating earlyage in situ strength development of concrete slabs. Construction and Building Materials, 29, 659-666.

Uva, G., Porco, F., Fiore, A., \& Mezzina, M. (2013). Proposal of a methodology for assessing the reliability of in situ concrete tests and improving the estimate of the compressive strength. Construction and Building Materials, 38, 72-83.

Vázquez-Herrero, C., Martínez-Lage, I., \& Sánchez-Tembleque, F. (2012). A new procedure to ensure structural safety based on the maturity method and limit state theory. Construction and Building Materials, 35, 393-398.

Yang, K. H. (2014). High-strength concrete application technology for nuclear facilities. Technical Report(1st), Department of Plant·Architectural Engineering, Kyonggi University, Suwon, Korea.

Zákoutský, J., Tydlitát, V., \& Černý, R. (2012). Effect of temperature on the early-stage hydration characteristics of Portland cement: A large-volume calorimetric study. Cement and Concrete Research, 36, 969-976. 